\title{
Pigments, Polyphenols and Antioxidant Activity of Leaf Extracts from Four Wild Rose Species Grown in Sicily
}

\author{
Francesca D’ANGIOLILLO, Michele Massimo MAMMANO, \\ Giancarlo FASCELLA* \\ CREA Research Centre for Plant Protection and Certification, S.S. 113 - Km 245.500, 90011 Bagheria, Palermo, \\ Italy; francescadangiolillo@libero.it; massimo.mammano@crea.gov.it; giancarlo.fascella@crea.gov.it (*correspondingauthor)
}

\begin{abstract}
Leaf methanolic extracts of four wild Rose species (Rosa canina L., R. corymbifera Borkh., $R$. micrantha Borrer ex Sm and $R$. sempervirens L.) grown in Sicily were analysed in order to evaluate differences among indigenous roses which could be used such as source of bioactive compounds and natural antioxidants. Leaves were harvested during two different periods (June and October) and their morphological characteristics were described. Leaf content of chlorophylls, total anthocyanins, total flavonoids, total polyphenols (Folin-Ciocalteu method) and antioxidant activity (DPPH method) were determined. Results showed that the contents of chlorophylls and carotenoids were higher in leaves of all species harvested in June than in those harvested in October. On the contrary, total anthocyanins of $R$. micrantha and $R$. corymbifera leaves were higher in October. Total polyphenol content was higher in leaves of all species were harvested in October. No difference in total flavonoids content was recorded between the two harvest periods but only among the four species. Antioxidant activity was generally high in leaf extracts of all species in both periods and, particularly, in $R$. micrantha leaves harvested in June. These outcomes seem to support the assessment that leaves harvested from some Sicilian wild roses may be used as promising source of healthy compounds and that their content varies with the species and harvest period.
\end{abstract}

Keywords: anthocyanins, antioxidants, carotenoids, chlorophylls, flavonoids, Sicilian roses

\section{Introduction}

The genus Rosa contains numerous species that are widely distributed in Europe, Asia, the Middle East and North America (Ercisli, 2005). In recent years, there has been an increasing interest in wild roses for economic and cultural reasons (Ercisli and Güleryüz, 2005; Kovacs et al., 2005; Uggla and Martinsson, 2005). Actually, native Rose species are generally important for maintaining biodiversity, increasing genetic variability to be exploited in breeding programmes, for ornamental purposes and for producing healthy functional foods as a source of secondary metabolites.

The chemical composition of Rose hip and leaf extracts is influenced by several factors including genotype, climatic conditions, and harvesting time (Scalzo et al., 2005). The different activities of plant extracts can be correlated to the different components present in these species such as phenols, carotenoids, vitamin C, tocopherol, pectin, and essential oils (Ercisli, 2007; Li et al., 2013). As described in the literature, secondary metabolites, especially phenolic compounds, flavonoids, tannins and terpenoids have potential antioxidant and antimicrobial activity (Wenzig et al., 2018).

It is well known that flavonoids and other phenolics ubiquitous in plants are essential parts of the human diet and that they exhibit a wide range of physiological properties, such as antiallergenic, anti-inflammatory, antimicrobial, anti-thrombotic, cardio-protective and vasodilatory effects (Middleton et al., 2000).

Rose extracts have been traditionally used in Chinese medicine for their antioxidant properties associated with the content of these metabolites which are particularly common in leaves and flowers (Fenglin et al., 2004; Sroka, 2005; Schmitzer et al., 2010). Rose species have also been also used in Turkey as a traditional medicine as tonic, diuretic (by boiling leaves and roots in water), expectorant and stomachic, and for the treatment of dyspepsia and diarrhea (Kultur, 2007).

Studies on the content of secondary metabolites in rose leaves (Nowak and Gawlik-Dziki, 2007; Bitis et al., 2008; Baydar and Baydar, 2013; Li et al., 2013) have confirmed 
that roses are a rich source of bioactive compounds. Nevertheless, except for the researches of Ghazghazi et al. (2010, 2012) and Ouerghemmi et al. (2016) regarding the antioxidant activities of leaf methanolic extracts of Tunisian wild roses, no report on the leaf composition of native roses from the Mediterranean basin is available in literature.

Some species of the genus Rosa (Rosaceae) are native to Sicily, Italy (Kurtto et al., 2004). They are usually hardy plants, showing different growing habits (bush, climbing, creeping), deciduous or evergreen, with leaves and hips of different sizes and shapes. Some species are widely spread from the sea level to the mountains whereas other grow in particular habitats only.

The Dog Rose (Rosa canina L.), an erect shrub growing up to $3.5 \mathrm{~m}$, generally used as an ornamental plant and for landscaping, is a valuable rootstock for many cultivated species and varieties and it is the most common in the Sicilian region (Fascella et al., 2015).

Rosa sempervirens L., with long creeping stems and dark leathery evergreen leaves (Ercisli, 2005), is also very common in the Sicilian areas though high altitudes represent a barrier to its extent as it is a cold-susceptible species (Fascella et al., 2015).

Rosa corymbifera Borkh., a deciduous shrub growing to 3 $\mathrm{m}$, shows similar morphological characteristics to that of $R$. canina and belongs to the same taxonomic group, but is less common in the Sicilian region than Dog Rose (Fascella et al., 2015).

Rosa micrantha Borrer ex Sm, a tall-growing shrub with arching branches, belongs to the Caninae section and is moderately common in Sicily (Fascella et al., 2015).

Although the valorisation of native species is important for several reasons (biodiversity maintenance, bioactive compounds production, environmental restoration), there are very few studies on Sicilian wild roses which only highlight regional distribution, habitats, and propagation techniques (Fascella et al., 2015), but no research has been conducted on the characterisation of metabolites extracted from leaves.

The aim of the present work was to evaluate the differences in pigment contents (chlorophylls, carotenoids and anthocyanins), other secondary metabolites (polyphenols, flavonoids) and the antioxidant activity of leaves of four different Sicilian Rose species ( $R$. canina, $R$. corymbifera, $R$. micrantha and $R$. sempervirens) collected in two different periods.

\section{Materials and Methods}

\section{Plant material and growth conditions}

The experiment was carried out over the period 2013-2015. Semi-hardwood cuttings (15 cm-long) were harvested during spring 2013 from wild-growing rose plants from different areas of Sicily, and were in vivo rooted after treatment with rooting substrates and hormones as reported by Fascella et al. (2015). Plants of Rosa canina (Can), $R$. corymbifera (Cor), $R$. micrantha (Mic) and $R$. sempervirens (Sem) propagated from cuttings were grown under openfield conditions at the experimental farm of the Council for
Agricultural Research and Economics, Research Centre for Plant Protection of Palermo (38 $5^{\prime}$ N, 1330' E, 23 m above sea level), in the North Western Sicily coastal area. The local climate was characterized by mild and moderately rainy winters, and hot dry summers. During the experiment mean $\mathrm{max} / \mathrm{min}$ temperatures of $31.2 / 11.4{ }^{\circ} \mathrm{C}$ were recorded in July and December, respectively. Average daily photosynthetic active radiation ranged from a minimum of 69.7 $\mu \mathrm{mol} \mathrm{m} \mathrm{s}^{-2}$ in December to a maximum of $1786.5 \mu \mathrm{mol} \mathrm{m}$ $s^{-1}$ in July.

The plants were grown in single rows at a plant density of 10 plants $\mathrm{m}^{-2}$. Water was supplied to plants through a drip irrigation system ( 1 dripper per plant, $21 \mathrm{~h}^{-1}$ ) during summer only, and irrigation management was driven by accumulated solar radiation (each irrigation started after reaching a preset radiation threshold) measured by a radiation sensor.

Sixty fully-expanded leaves were randomly collected from two year-old plants (10 leaves per plant) of the four species in June (T1) and October (T2) 2015, and differences in the content of pigments (chlorophylls, carotenoids and anthocyanins), total polyphenols and total flavonoids, and in radical scavenging activity were evaluated.

\section{Morphological description}

For each of the studied species, main morphological characteristics of leaves (shape, margin, rachis length, number of leaflets per leaf, leaflet length and width) were described. A total of 150 leaves per species were randomly selected from different levels of the canopy and measured. As regards leaf margin, the presence of a simple or a double order of teeth was detected. Leaf rachis length was measured from the end of the apical leaflet to the end of the petiole. Leaflet length was measured from lamina tip to the point of intersection of the lamina and the rachis, along the midrib of the lamina. Leaflet width was measured from end-to-end between the widest lobes of the lamina perpendicular to the lamina mid-rib.

Determination of pigments (chlorophylls, carotenoids and anthocyanins)

Chlorophylls ( $a, b$ and total) and carotenoids of the leaf content was extracted and determined using the method described by Lichtenthaler (1987). Fresh leaf material (200 $\mathrm{mg}$ ) of the four species harvested in the two periods (CanT1, CorT1, MicT1, SemT1 and CanT2, CorT2, MicT2, SemT2) was extracted overnight in $5 \mathrm{ml}$ of pure methanol at $4{ }^{\circ} \mathrm{C}$ in the dark. The absorbance of the extracts at 665,652 , and $470 \mathrm{~nm}$ was determined using a spectrophotometer (Beckman DU 530 Life Science UV/Vis, Ramsey, MN, USA).

The relative quantity of chlorophyll present in leaf tissues, expressed as SPAD index, was also determined by means of a portable chlorophyll meter SPAD-502 (KonicaMinolta corporation, Ltd., Osaka, Japan); sixty fully expanded leaves were randomly selected, measured and averaged to a single value for each species.

Total anthocyanins content was determined according to the method of Cheng and Breen (1991) with slight modifications. Fresh material $(200 \mathrm{mg})$ was extracted in a volume $(99 / 1 \% \mathrm{v} / \mathrm{v})$ of $\mathrm{MeOH} / \mathrm{HCl}$ with the addition of 
404

$2 / 3$ volume of distilled water. A volume of chloroform was added to remove chlorophylls. The samples were mixed and centrifuged (Hettich Universal 320R, Tuttingen, Germany) at $12.000 \mathrm{rpm}$ for $20 \mathrm{~min}$ at room temperature. The anthocyanins present in the aqueous phase were recovered, and absorption was determined spectrophotometrically at $535 \mathrm{~nm}$. Calculation of the anthocyanin content was based on the standard curve prepared using cyanidine chloride at different concentrations $\left(1-200 \mu \mathrm{g} \mathrm{ml}^{-1}\right)$. The content was expressed as $\mathrm{mg} \mathrm{CC} / 100 \mathrm{~g}$ of fresh weight (FW). Mean values were obtained from three independent experiments.

\section{Methanolic extracts}

Fresh leaves $(200 \mathrm{mg})$ of the four Rose species harvested in the two periods were pulverised and homogenised in a mortar with $2 \mathrm{ml}$ of $70 \%(\mathrm{v} / \mathrm{v})$ methanol to facilitate the extraction. After 30 min of incubation on ice, the extracts were centrifuged at $12.000 \mathrm{rpm}$ for $10 \mathrm{~min}$ at room temperature. For each samples, the supernatant (methanol extract) was collected to be used for the determination of total polyphenols, total flavonoids and the antiradical activity.

\section{Determination of polyphenols content}

Total polyphenols were determined using the FolinCiocalteu colorimetric method (Singleton and Rossi, 1965). Leaf extracts were diluted $(1: 1 \mathrm{v} / \mathrm{v})$ with $70 \%(\mathrm{v} / \mathrm{v})$ methanol before use. An aliquot $(0.005 \mathrm{ml})$ of the diluted extract was mixed with Folin-Ciocalteau's reagent $(0.5 \mathrm{ml})$ and kept for $5 \mathrm{~min}$ at room temperature. Then, $0.45 \mathrm{ml}$ of a $7.5 \%(\mathrm{w} / \mathrm{v}) \mathrm{Na}_{2} \mathrm{CO}_{3}$ solution was added to the mix and incubated for $2 \mathrm{~h}$ in the dark at $20{ }^{\circ} \mathrm{C}$. Finally, the absorbance of the samples was measured at $765 \mathrm{~nm}$. Chlorogenic acid (0.05-0.9 mM) was used to calculate the standard curve, and the results were expressed as $\mathrm{mg}$ of chlorogenic acid equivalents per $\mathrm{g}$ of fresh weight (mg $\mathrm{CAE} / \mathrm{g} \mathrm{FW}$ ). Experiments were carried out in triplicate.

\section{Determination of flavonoids content}

Total flavonoids were determined using the colorimetric method of Kim et al. (2003). For each sample, $345 \mu \mathrm{l}$ of distilled water and $75 \mu \mathrm{l}$ of $5 \%(\mathrm{w} / \mathrm{v})$ sodium nitrite $\left(\mathrm{NaNO}_{2}\right)$ were added to $5 \mu \mathrm{l}$ of methanol extract. After 5 min of incubation, $75 \mu \mathrm{l}$ of $10 \%(\mathrm{w} / \mathrm{v})$ of aluminum trichloride hexahydrate $\left(\mathrm{AlCl}_{3}-6 \mathrm{H}_{2} \mathrm{O}\right)$ was added to the sample. Successively, $500 \mu \mathrm{l}$ of $1 \mathrm{M}$ sodium hydroxide $(\mathrm{NaOH})$ was added after $5 \mathrm{~min}$. The samples were incubated for $15 \mathrm{~min}$ and the absorbance was read at 415 $\mathrm{nm}$ with the UV/VIS spectrophotometer. Quantitative determination was made using a calibration curve with quercetin (used as standard) 1:1 (w/v) dissolved in absolute methanol and the results were expressed as mg of quercetin equivalent per $\mathrm{g}$ of fresh weight (mg QE/g FW). Each analysis was repeated three times.

\section{Evaluation of radical scavenging activity}

The antiradical activity of leaves extracts in the two harvest periods was determined by the 2,2-diphenyl-1picrylhydrazyl radical (DPPH) method with slight modifications (Brand-Williams et al., 1995). An aliquot $(0.335 \mathrm{ml})$ of a $0.25 \mathrm{mM}(\mathrm{w} / \mathrm{v})$ methanolic solution DPPH was added to $0.665 \mathrm{ml}$ of the sample at different concentrations (50-150-250-500 $\mu \mathrm{g} / \mathrm{ml})$, and incubated at room temperature in the dark for $30 \mathrm{~min}$. The activity was measured as a decrease in absorbance at $517 \mathrm{~nm}$. The percent inhibition of the DPPH radical by the samples was calculated according to the formula:

$\%$ inhibition $=\left[\left(\mathrm{A}_{\text {blank }}-\mathrm{A}_{\text {sample }}\right) / \mathrm{A}_{\text {blank }}\right] \times 100$

where $A_{\text {blank }}$ is the absorbance of the DPPH and $A_{\text {sample }}$ is the absorbance of the samples. The extract concentration (IC50 expressed as $\mu \mathrm{g} \mathrm{FW} / \mathrm{ml}$ ) providing $50 \%$ of antioxidant activities was calculated by plotting a graph of inhibition percentage against extract concentration. All determinations were performed in triplicate.

\section{Statistical analysis}

All the data reported in the tables and in the figures are the mean values \pm standard error of three independent experiments with three replications each. The statistical differences among leaf extracts of Rose species in the two harvest periods were obtained by subjecting data to a twoways analysis of variance with Student-Newmann-Keuls Multiple Comparison post-hoc test at $\mathrm{p}<0.01$ and $\mathrm{p}<0.05$. The variability of the content of pigments and bioactive compounds among Rosa species and between harvesting periods was assessed by the use of principal component analysis (PCA) and cluster analysis based on the Euclidean distance; these analyses were performed by means of the software package Statistica (Statsoft Inc., Tulsa, OK, USA).

\section{Results and Discussion}

\section{Morphological characteristics}

The main morphological characteristics of leaves of all species were reported in Table 1 and Fig. 1. In particular, three species ( $R$. canina, $R$. corymbifera and $R$. micrantha) showed an elliptic-ovate shape with rounded lobes at the base of the lamina and only $R$. sempervirens was characterized by acuminate (lanceolate) leaves. As regards leaf margin, Can and Mic showed simple coarsely dentate leaves having a single series of large teeth, Sem produced finely toothed leaves while Cor evidenced doubly serrate leaves as each tooth bearing smaller teeth (Table 1, Fig. 1). No significant differences were recorded among the species with regard to the length of leaf rachis, which varied from a minimum of 5.2 to a maximum of $3.2 \mathrm{~mm}$ for Mic and Sem, respectively. Limited variations among the Rose species were also observed as regards the number of leaflets per leaf which ranged from 5.1 (Sem) to 6.5 (Can). Leaflet length was higher in Can $(50.7 \mathrm{~mm})$ and lower in Cor $(30.7 \mathrm{~mm})$ (Table 1); leaflet width varied from a maximum of $30.3 \mathrm{~mm}$ (Can) to a minimum of $16.1 \mathrm{~mm}$ (Sem).

\section{Pigments (chlorophylls, carotenoids and anthocyanins)}

The leaf pigments content of the four Sicilian roses harvested in the two periods is reported in Table 2. Leaf chlorophyll content was mainly affected by the harvesting period as the total chlorophyll content of all species was higher in June ( $0.92 \mathrm{mg} / \mathrm{g} \mathrm{FW}$, on average) compared to that measured in October $(0.76 \mathrm{mg} / \mathrm{g} \mathrm{FW}$, on average). Differences among the species were higher in June (from 0.76 to $1.11 \mathrm{mg} / \mathrm{g} \mathrm{FW}$ for $R$. micrantha and $R$. corymbifera, respectively) and lower in October (from 0.66 to $0.83 \mathrm{mg} / \mathrm{g}$ 
Table 1. Main morphological characteristics of $R$. canina L. (Can), R. corymbifera Borkh. (Cor), R. micrantha Borrer ex Sm (Mic) and $R$. sempervirens L. (Sem) leaves

\begin{tabular}{|c|c|c|c|c|c|c|}
\hline Species abbreviation & Shape & Margin & Rachis length (mm) & Leaflet per leaf(No.) & Leaflet length $(\mathrm{mm})$ & Leaflet width $(\mathrm{mm})$ \\
\hline Can & Elliptic-ovate & Dentate & $5.1 \pm 0.02$ & $6.5 \pm 0.03$ & $50.7 \pm 0.1$ & $30.3 \pm 0.3$ \\
\hline Cor & Elliptic-ovate & Doubly serrate & $4.5 \pm 0.01$ & $6.1 \pm 0.02$ & $38.7 \pm 0.3$ & $21.7 \pm 0.2$ \\
\hline Mic & Elliptic & Dentate & $5.2 \pm 0.03$ & $5.9 \pm 0.04$ & $44.4 \pm 0.2$ & $27.0 \pm 0.4$ \\
\hline Sem & Acuminate & Denticulate & $3.2 \pm 0.04$ & $5.1 \pm 0.02$ & $45.2 \pm 0.1$ & $16.1 \pm 0.5$ \\
\hline
\end{tabular}

Table 2. Chlorophylls $(a, b$, total) and carotenoids content $(\mathrm{mg} / \mathrm{g} \mathrm{FW})$ in methanolic extracts of $R$. canina (Can), $R$. corymbifera (Cor), $R$. micrantha (Mic) and $R$ sempervirens $(\mathrm{Sem})$ leaves harvested in June $\left(\mathrm{T}_{1}\right)$ and October $\left(\mathrm{T}_{2}\right)$

\begin{tabular}{|c|c|c|c|c|c|c|c|c|}
\hline \multirow{2}{*}{$\begin{array}{l}\text { Species } \\
\text { abbrev. }\end{array}$} & \multicolumn{3}{|c|}{$\mathrm{T}_{1}$} & \multicolumn{5}{|c|}{$\mathrm{T}_{2}$} \\
\hline & Chl $a$ & Chl $b$ & Chl total & Carotenoids & Chl $a$ & Chl $b$ & Chl total & Carotenoids \\
\hline Can & $0.35 \pm 0.03^{a}$ & $0.48 \pm 0.03^{b}$ & $0.83 \pm 0.05^{\mathrm{a}}$ & $25.79 \pm 0.44^{a}$ & $0.25 \pm 0.03^{a}$ & $0.49 \pm 0.03^{b}$ & $0.74 \pm 0.06^{a}$ & $19.76 \pm 1.34^{\mathrm{a}}$ \\
\hline Cor & $0.43 \pm 0.03^{b}$ & $0.68 \pm 0.03^{d}$ & $1.11 \pm 0.01^{\mathrm{b}}$ & $26.57 \pm 2.91^{a}$ & $0.29 \pm 0.03^{\mathrm{a}}$ & $0.53 \pm 0.02^{b}$ & $0.82 \pm 0.06^{\mathrm{a}}$ & $19.83 \pm 1.26^{\mathrm{a}}$ \\
\hline Mic & $0.42 \pm 0.02^{b}$ & $0.34 \pm 0.01^{\mathrm{a}}$ & $0.76 \pm 0.02^{\mathrm{a}}$ & $26.96 \pm 1.57^{\mathrm{a}}$ & $0.32 \pm 0.06^{\mathrm{a}}$ & $0.35 \pm 0.02^{\mathrm{a}}$ & $0.66 \pm 0.07^{\mathrm{a}}$ & $19.16 \pm 1.81^{a}$ \\
\hline Sem & $0.43 \pm 0.08^{b}$ & $0.57 \pm 0.09^{c}$ & $1.00 \pm 0.07^{\mathrm{b}}$ & $27.25 \pm 0.57^{\mathrm{a}}$ & $0.32 \pm 0.03^{\mathrm{a}}$ & $0.51 \pm 0.04^{\mathrm{b}}$ & $0.83 \pm 0.06^{b}$ & $21.0 \pm 0.32^{\mathrm{a}}$ \\
\hline
\end{tabular}

Note: Each value is expressed as the mean \pm SD of three replicate determination $(\mathrm{p}<0.05)$

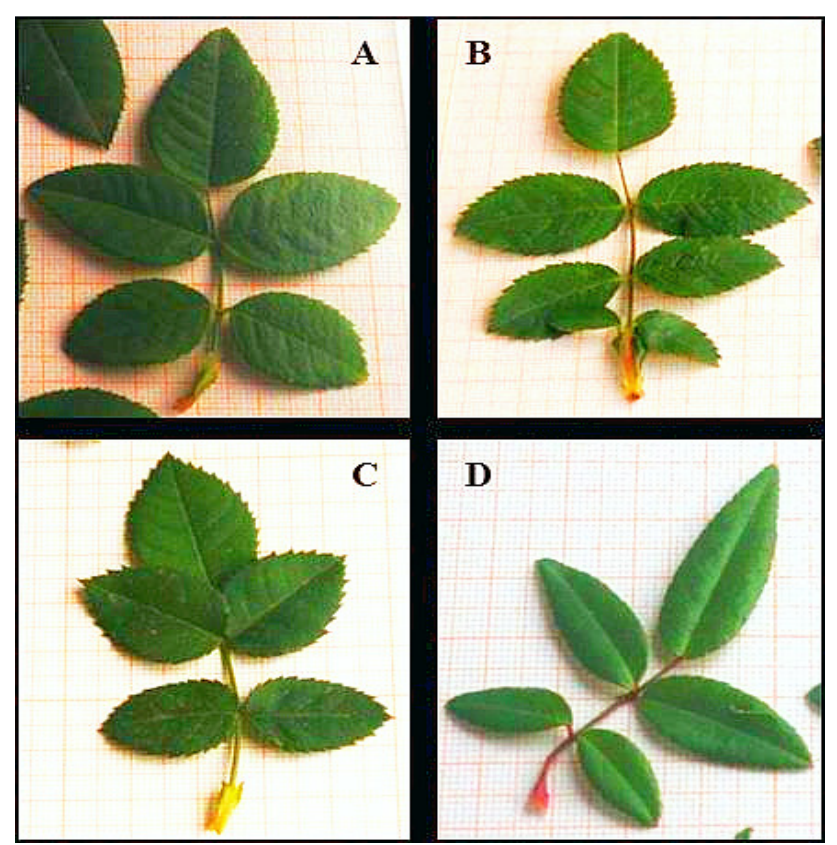

Fig. 1. Fully-expanded detached leaves of $R$. canina (A), $R$. corymbifera (B), R. micrantha (C) and $R$. sempervirens (D)

FW for $R$. micrantha and $R$. sempervirens, respectively) (Table 2). The leaf content of carotenoids was different in the two harvesting periods but not among Rose species: in all genotypes, the carotenoid content recorded in June was higher (average $26.6 \mathrm{mg} / \mathrm{g} \mathrm{FW}$ ) than that measured in October $(19.9 \mathrm{mg} / \mathrm{g} \mathrm{FW})$ while the species studied showed no relevant differences (on average $23.3 \mathrm{mg} / \mathrm{g}$ ) (Table 2).

Sparinska and Rostoks (2012) observed high variations in leaf the chlorophyll content of Latvian $R$. rugosa cultivars, ranging between 1.34 and $1.93 \mathrm{mg} / \mathrm{g}$, whereas carotenoids varied between 0.3 and $0.52 \mathrm{mg} / \mathrm{g}$, and found that differences in the leaf content of these two pigments were mainly associated with the genotype. Our results on the relationship between leaf pigments content and harvesting time are in line with those of Adumitresei et al. (2011), who studied foliar assimilating pigments during the ontogenetic development of some wild and cultivated Rose species, and observed that chlorophylls of spontaneously growing species ranged between 2.51 and $1.32 \mathrm{mg} / 100 \mathrm{~g} \mathrm{FW}$ during the vegetative stage and between 2.29 and $1.13 \mathrm{mg} / 100 \mathrm{~g} \mathrm{FW}$ during the fruit ripening stage. The same authors also reported that leaf carotenoids were extremely low in wild species (<ppm per $\mathrm{mg} / 100 \mathrm{~g} \mathrm{FW}$ ), while cultivars showed values of $0.1-0.2 \mathrm{mg} / 100 \mathrm{~g} \mathrm{FW}$. Likewise, Monder et al. (2014) reported that the pigment content of leaves of $R$. gallica mother plants was mainly determined by the phenological stage of shoots, as the highest amounts of photosynthetic pigments were observed just after petal fall, while chlorophyll $a$ decreased at the end of growth period (August), thereby changing the chlorophylls/carotenoids ratio.

It is possible that different factors such as solar radiation could be responsible for the quantitative variation of leaf carotenoids as these pigments are able to protect leaves from the excess of light, as shown in other studies (González et al., 2007).

The relative chlorophyll content (SPAD index) of leaves was also affected by harvesting period and species: actually, SPAD of $R$. sempervirens leaves did not vary between June and October (average 35.3), whereas SPAD values of the other species were higher in June (average 38.5) and lower in October (average 29.5) (Fig. 2).

The leaf concentration of total anthocyanins was influenced by species, with $R$. micrantha showing the highest content (12.2 mg cyanidine chloride/100g FW) compared to the other three species (average $9.4 \mathrm{mg}$ $\mathrm{CC} / 100 \mathrm{~g}$ FW) (Fig. 3). Leaf anthocyanins content was also affected by the harvesting periods as $R$. micrantha and $R$. corymbifera evidenced higher values in leaves harvested in October (14.4 and $12.7 \mathrm{mg} \mathrm{CC/100g} \mathrm{FW} \mathrm{for} \mathrm{Mic} \mathrm{and} \mathrm{Cor,}$ respectively) than those measured in leaves harvested in June (10.0 and $5.6 \mathrm{mg} \mathrm{CC/100g} \mathrm{FW)} \mathrm{(Fig.} \mathrm{3),} \mathrm{whereas} \mathrm{no}$ significant differences were recorded in leaves of $R$. canina (8.8 and $9.6 \mathrm{mg} \mathrm{CC} / 100 \mathrm{~g}$ FW for CanT1 and CanT2, respectively) and $R$. sempervirens (9.7 and $10.3 \mathrm{mg}$ CC/100g FW for SemT1 and SemT2, respectively) harvested in the two periods. 
406

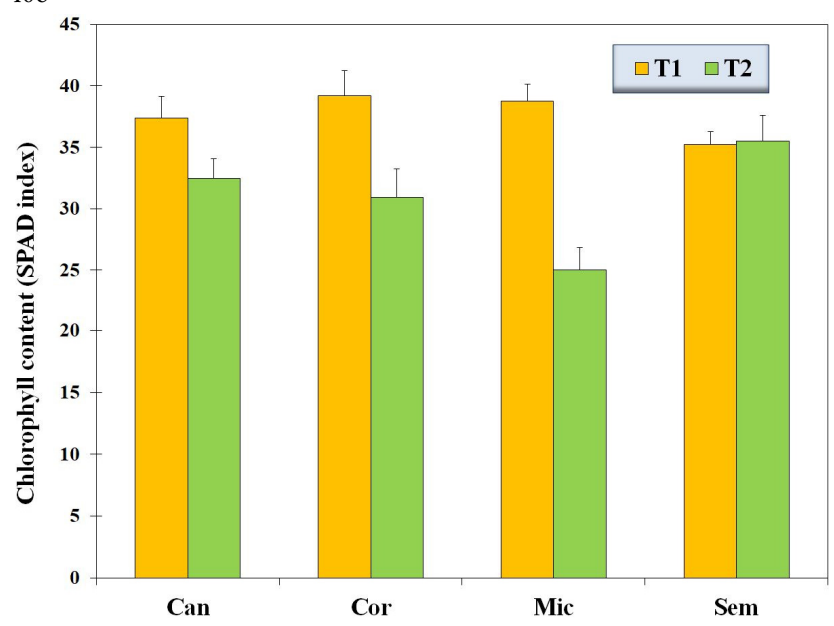

Fig. 2. Relative chlorophyll content (SPAD index) of $R$. canina (Can), $R$. corymbifera (Cor), $R$. micrantha (Mic) and $R$. sempervirens (Sem) leaves harvested in June $\left(\mathrm{T}_{1}\right)$ and October $\left(T_{2}\right)$. Each value is expressed as the mean \pm SD of three replicate determination $(\mathrm{p}<0.05)$

Anthocyanins have a physiological importance because they are able to protect leaves from photo-oxidative injuries, both by shielding chloroplasts from excess high-energy quanta and by scavenging reactive oxygen species, without significantly compromising photosynthesis.

Total polyphenols and flavonoids

Methanol extracts from Sicilian Rose leaves harvested in June (T1) and October (T2) were used to assess the presence and the contents of polyphenols and flavonoids. The concentration of total polyphenols in rose leaves was affected both by harvesting periods and by species as leaves harvested in June had a lower content than those harvested in October (36.5 and $52.1 \mathrm{mg}$ chlorogenic acid equivalents/g FW, respectively) (Table 3 ). Across species, $R$. micrantha evidenced a higher polyphenol concentration (55.4 mg CAE/g FW) compared to the content of the other species (average $40.5 \mathrm{mg} \mathrm{CAE} / \mathrm{g} \mathrm{FW}$ ).

The variations in the polyphenol content of leaf extracts of Rose species seem to be confirmed by different authors. When evaluating the phenolic content of Polish rose leaf extracts, Nowak and Gawlik-Dziki (2007) observed that total phenolics varied among species ranging from $5.7 \%$ to $15.2 \%$ gallic acid equivalents in dry material of $R$. rugosa and $R$. canina, respectively. In addition, Ozsoy et al. (2013) estimated that total phenolics in $R$. horrida leaves were $152.0 \mathrm{mg} \mathrm{GAE} / \mathrm{g}$ extract; this value was lower than both the value (489.76 mg GAE/g) reported for $R$. agrestis leaves (Bitis et al., 2008) and the range of 478.3 to $530.4 \mathrm{mg}$ $\mathrm{GAE} / \mathrm{g}$ found for the leaf extracts of $R$. damascena (Baydar and Baydar, 2013). Ouerghemmi et al. (2016) described that total polyphenols ranged from 147 ( $R$. moschata) to 240 ( $R$. sempervirens) $\mu \mathrm{g}$ GAE/mg dry extract, thus confirming that the qualitative and quantitative polyphenol composition is dependent on plant species as well as on environmental conditions. Recently, Cunja et al. (2014) have reported more than 50 different phenolic compounds present in leaves of four different Rosa species, belonging to the subclasses of flavonols, phenolic acids and their derivatives with quinic acid and various sugars. The influence of genotype on leaf polyphenol content was also evidenced by Ghazghazi et al. $(2010,2012)$, who reported that the phenol content of leaf methanolic extracts of Tunisian wild roses ranged from 5.4 to $9.2 \mathrm{GAE} / \mathrm{ml}$ for $R$. canina and from 1.2 to $7.5 \mathrm{mg} \mathrm{GAE} / \mathrm{ml}$ for $R$. sempervirens, as several factors seemed to be responsible for such variability, including altitude, developmental stage and climate. Moreover, the wide variations in the total phenolics contents of the different species may be due to the complexity of these groups of compounds, and the methodologies used for the extraction and the analysis (Kalt et al., 2001).

The total content of flavonoids of Rose leaves is reported in Table 3. Leaf flavonoids content was not affected by the harvesting period as limited differences were recorded between June and October harvest (14.4 and 18.3 $\mathrm{mg}$ quercetin equivalent/g FW, respectively). Flavonoids content was moderately influenced by species, with higher value recorded in $R$. corymbifera leaves $(20.0 \mathrm{mg} \mathrm{QE} / \mathrm{g} \mathrm{FW})$ than in leaves of the other species (average $15.1 \mathrm{mg} \mathrm{QE} / \mathrm{g}$ FW) (Table 3).

Ozsoy et al. (2013) observed that the flavonoid content of $R$. horrida leaf extracts was $67.6 \mathrm{mg}$ catechin equivalents/g extract or $9.7 \mathrm{mg} / \mathrm{dry}$ weight. Nowak and Gawlik-Dziki (2007) reported that the total amount of flavonols, calculated as the sum of quercetin and kaempferol levels, in rose leaves after hydrolysis ranged from 5.5 to 19.0 $\mathrm{mg} / \mathrm{g} \mathrm{DW}$. Ghazghazi et al. $(2010,2012)$ found that the flavonoid content was heterogeneous in $R$. canina and $R$. sempervirens leaves harvested from different locations of Tunisia, and varied from 0.11 to $0.41 \mathrm{mg}$ rutin equivalents/ $\mathrm{ml}$ extract, with no correlation with the phenol content. The authors observed that the accumulation of these compounds was affected by climate, developmental stage and collection time.

Table 3. Total poliphenols (mg CAE/g FW), total flavonoids content (mg QE/g FW) and antioxidant activity (IC50 expressed as $\mu \mathrm{g} \mathrm{FW/ml)} \mathrm{in}$ methanolic extracts of $R$. canina (Can), R. corymbifera (Cor), $R$. micrantha (Mic) and $R$ sempervirens $(\mathrm{Sem})$ leaves harvested in June $\left(\mathrm{T}_{1}\right)$ and October $\left(\mathrm{T}_{2}\right)$

\begin{tabular}{|c|c|c|c|c|c|c|}
\hline \multirow{2}{*}{$\begin{array}{l}\text { Species } \\
\text { abbrev. }\end{array}$} & \multicolumn{3}{|c|}{$\mathrm{T}_{1}$} & \multicolumn{3}{|c|}{$\mathrm{T}_{2}$} \\
\hline & Polyphenols & Flavonoids & IC 50 & Polyphenols & Flavonoids & IC50 \\
\hline Can & $36.1 \pm 0.77^{\mathrm{b}}$ & $13.1 \pm 1.02^{\mathrm{a}}$ & $140.7 \pm 7.87^{a}$ & $46.8 \pm 3.68^{a}$ & $14.7 \pm 1.54^{\mathrm{a}}$ & $266.9 \pm 19.6^{b}$ \\
\hline Cor & $35.1 \pm 1.80^{\mathrm{b}}$ & $15.9 \pm 1.76^{\mathrm{a}}$ & $171.2 \pm 6.4^{b}$ & $47.4 \pm 0.14^{\mathrm{a}}$ & $24.1 \pm 1.81^{\mathrm{c}}$ & $181.5 \pm 2.4^{\mathrm{a}}$ \\
\hline Mic & $43.3 \pm 3.52^{c}$ & $15.0 \pm 0.90^{a}$ & $147.1 \pm 2.6^{\mathrm{a}}$ & $67.5 \pm 2.62^{b}$ & $17.1 \pm 0.95^{b}$ & $191.8 \pm 7.7^{\mathrm{a}}$ \\
\hline Sem & $31.3 \pm 0.36^{\mathrm{a}}$ & $13.6 \pm 1.05^{\mathrm{a}}$ & $218.4 \pm 1.2^{c}$ & $46.5 \pm 0.01^{\mathrm{a}}$ & $17.4 \pm 0.92^{b}$ & $259.6 \pm 12.7^{\mathrm{b}}$ \\
\hline
\end{tabular}

Note: Data are the mean values \pm SD of three independent experiments with triplicates $(\mathrm{p}<0.05)$. 
Considering that polyphenols and flavonoids also exhibit important antioxidant activities (Kähkönen et al., 1999) as well as anti-inflammatory and antimicrobial properties, such quantitative differences between Sicilian roses and wild rose species from other countries may provide widely diverse results.

\section{Radical scavenging activity}

The method used to determine the radical scavenging activity of Rose leaf extracts is based on the reduction of DPPH solution to the non-radical form (Brand-Williams $e t$ al., 1995). This analysis is rapid, sensitive and generally used for screening the antioxidant capacity of different plant extracts (Fenglin et al., 2004) as lower IC50 values correspond to a higher antioxidant activities and vice versa. The radical scavenging activity of Rose leaf extracts was affected by harvest period as well as by species, with leaves of all species harvested in June showing lower IC 50 values, i.e. higher antioxidant activity, $(169.3 \mu \mathrm{g} \mathrm{FW} / \mathrm{ml})$ than those harvested in October $(224.9 \mu \mathrm{g} \mathrm{FW} / \mathrm{ml})$. Among the four Sicilian roses, $R$. micrantha leaves showed lower IC50 in both harvest periods (average $169.4 \mu \mathrm{g} \mathrm{FW} / \mathrm{ml}$ ) than those from the other species $(206.4 \mu \mathrm{gW} / \mathrm{ml}$, on average).

Our results on the higher radical scavenging activity of leaves from the June harvest seem to be in contrast with the lower content of polyphenols in the same period, given that these bioactive compounds usually show a positive correlation with antioxidant capacity, as described by other authors (Gao et al., 2000; Wenzig et al., 2008). Therefore, the antioxidant capacity of leaf extracts in the present study was inversely proportional to the content of polyphenols (negative correlation).

Similarly to our results, Ghazghazi et al. (2010) did not find any correlation between the amounts of phenols in samples and the antioxidant activity (IC50) of $R$. canina leaf methanolic extracts from different Tunisian areas. These authors also stated that different phenols possess diverse activity depending on their chemical structure. In fact, phenolic compounds comprise one of the largest groups of plant metabolites and they can be divided into at least 10 different classes based on their general chemical structure (Kondratyuk and Pezzuto, 2004). The difference in free

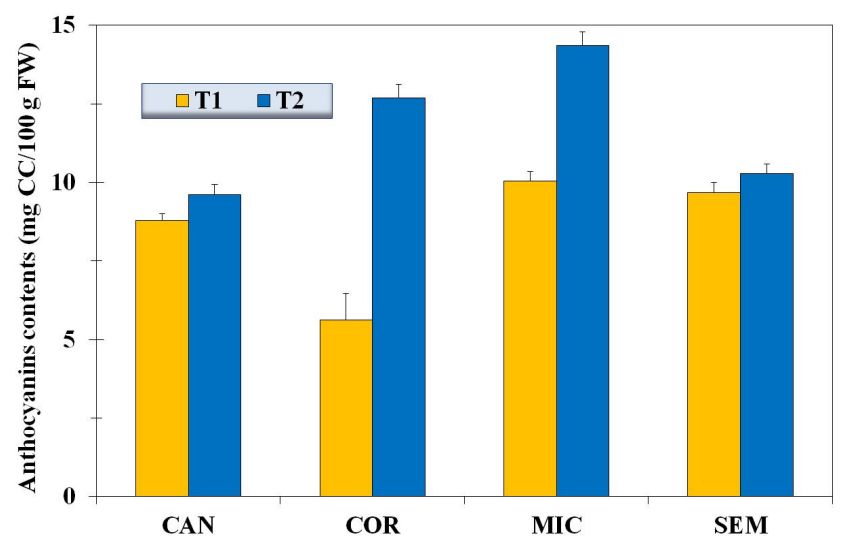

Fig. 3. Anthocyanins contents (mg CC/100 g FW) in methanolic extracts of $R$. canina (Can), $R$. corymbifera (Cor), $R$. micrantha (Mic) and R. sempervirens (Sem) leaves harvested in June $\left(T_{1}\right)$ and October $\left(T_{2}\right)$. Data are the mean values $\pm S D$ of three independent experiments with triplicates $(\mathrm{p}<0.05)$ radical scavenging capacity among these classes of phenolic compounds may partially explain the absence of correlation between the increase in leaf polyphenol content measured in October and the lower antioxidant activity of extracts from leaves harvested in the same period. Diverse groups of phenols potentially present in extracts are responsible for the diversity of antioxidant activity. Moreover, Parejo et al. (2002) reported that different factors can affect the antioxidant activity of the extracts such as the presence of a mixture of antioxidant and pro-oxidant molecules with a synergistic action among compounds, the different methods used to analyse the activity, as well as the variability of antioxidant properties of individual compounds within the group.

The influence of genotype on the radical scavenging activity of Sicilian roses is also confirmed by Nowak and Gawlik-Dziki (2007) who reported that all of the examined Polish rose leaf extracts showed high antioxidant activity in the DPPH assay, as the inhibition values ranged from $83.4 \%$ ( $R$. rugosa) to $95.7 \%$ ( $R$. corymbifera). Ouerghemmi et al. (2016) found interspecific differences in antioxidant activity among Tunisian wild roses, with the highest mean values for DPPH recorded for ethanolic leaf extracts of $R$. sempervirens $\left(0.9 \mathrm{mmol}\right.$ Trolox equivalents $\mathrm{g}^{-1}$ dry extract) and for methanolic leaf extracts of $R$. canina (2.4 mmol TE $\mathrm{g}^{-1} \mathrm{DE}$ ). Moreover, Ozsoy et al. (2013) reported that $R$. horrida leaf extracts showed a high DPPH radical scavenging activity, with EC50 being $0.62 \mathrm{mg} / \mathrm{ml}$.

\section{Statistical evaluation of biochemical data}

Principal component analysis (PCA) of the spectrophotometric data was performed for easier interpretation of the results and for evaluating variability in pigments and bioactive compounds among Rose species and between harvesting periods. Fig. 4 shows the first two principal components ( $\mathrm{C} 1$ and $\mathrm{C} 2$ ) which explained $77.8 \%$ of the total variance, with $\mathrm{C} 1$ and $\mathrm{C} 2$ accounting for $59.7 \%$ and $18.0 \%$, respectively. The samples were divided into two main groups: leaves of the four species harvested in October (CanT2, CorT2, MicT2 and SemT2) were positioned together in the positive region of the first principal component (C1) (Fig. 4); these samples had higher values

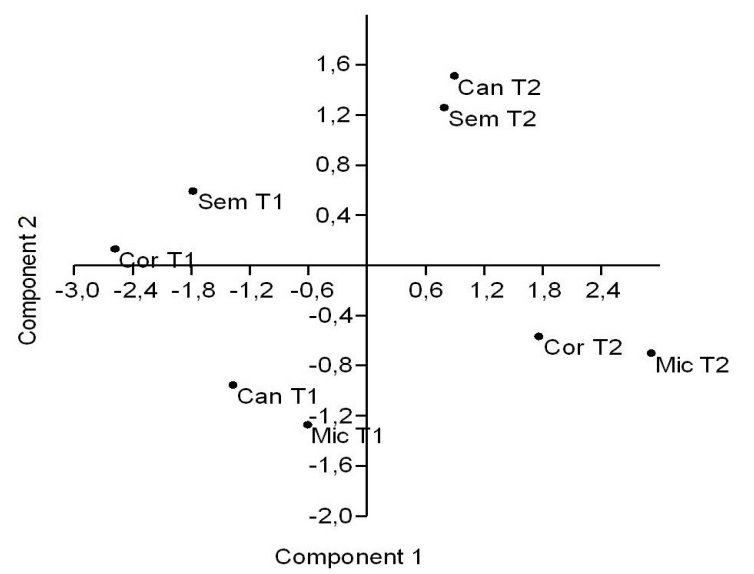

Fig. 4. Principal component analysis of Sicilian Rose leaf extracts: contribution of pigments and bioactive compounds for each Rose species (Can, Cor, Mic and Sem) and harvesting $\operatorname{period}\left(\mathrm{T}_{1}\right.$ and $\left.\mathrm{T}_{2}\right)$ 


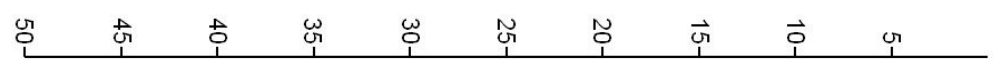

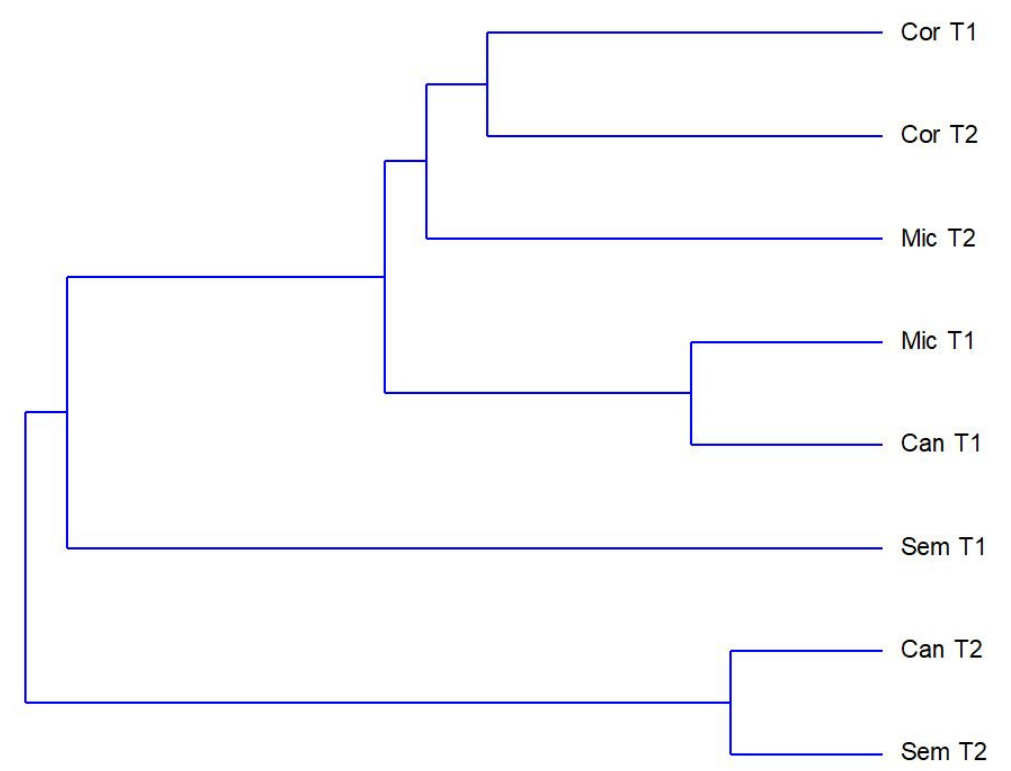

Fig. 5. Cluster analysis based on Euclidean distance of Sicilian Rose leaf extracts in relation to pigments and bioactive compounds content of $R$. canina (Can), R. corymbifera (Cor), $R$. micrantha (Mic) and $R$. sempervirens (Sem) leaves harvested in June ( $\mathrm{T}_{1}$ ) and October $\left(\mathrm{T}_{2}\right)$

for total anthocyanins, total polyphenols and antioxidant activity. Leaves of all species harvested in June (CanT1, CorT1, MicT1 and SemT1) were located in the negative side of $\mathrm{C} 1$; these samples had higher amounts of chlorophylls and carotenoids. However, Mic and Cor showed lower differences between the two harvesting periods than the other two species (Fig. 4).

PCA results were confirmed by the cluster analysis performed using the Euclidean distance, which revealed variability in the content of secondary metabolites among Rosa species and between harvesting periods, showing clearly separated groups of leaf extracts (Fig. 5). The resulting dendrogram allowed to subdivide samples in four groups: CorT1, CorT2 and MicT2; MicT1 and CanT1; SemT1 standing alone; and CanT2 and SemT2, and confirmed that $R$. corymbifera performed well in both periods, as did $R$. micrantha, that showed reduced Euclidean distances although it belonged to separate groups (MicT1 and MicT2). Higher distances recorded for Dog and Sem in the two periods (Fig. 5) seem to check the influence of harvesting periods on the leaf metabolites content of these two species.

\section{Conclusions}

Results of the present experiment suggest that the leaves of Sicilian roses, in particular $R$. micrantha, are a promising source of bioactive compounds with antioxidant properties, such as anthocyanins and phenolic compounds. The differences observed among the Rose species native to Sicily in terms of photosynthetic pigments, total polyphenols and antioxidant activity are supposedly due to genetic derivation as plants were grown using the same cultivation techniques and under the same climatic conditions.
The leaf harvesting period significantly affected the leaf content of metabolites i.e. total anthocyanins and total polyphenols increased from June to October, whereas the content of pigments and the antioxidant activity of leaf extracts decreased, probably because the metabolism of plants was moved to fruit ripening. The results suggested that June was the best period for harvesting wild rose leaves for higher contents of chlorophylls and carotenoids, October was particularly favourable for harvesting leaves rich in anthocyanins and polyphenols, whereas antiradical activity was high in leaves harvested in both periods.

Our findings further support the assessment that some spontaneously growing roses from south Mediterranean countries can be used as promising sources of healthy compounds and, considering the radical scavenging activity evaluated by DPPH assay, leaf extracts of Sicilian roses could be exploited as new plant material for natural antioxidants.

\section{Acknowledgements}

This work was supported by the Italian Ministry of Agriculture, Alimentation and Forestry Policies through the project "Plant Genetic Resources" (RGV/FAO).

\section{References}

Adumitresei L, MagdalenaZM,Zenovia O, Irina B(2011). Observations on the foliar assimilating pigments content for wild and garden roses. Journal of Plant Development 18:47-54.

Baydar NG, Baydar H (2013). Phenolic compounds, antiradical activity and antioxidant capacity of oil-bearing rose (Rosa damascena Mill.) extracts. Industrial Crops and Products 41:375-380. 
Bitis L, Kultur S, Melikoglu G, Ozsoy N, Can A (2010). Flavonoids and antioxidant activity of Rosa agrestis leaves. Natural Product Research 24:580-589.

Brand-Williams W, Cuvelier ME, Berset C (1995). Use of a free radical method to evaluate antioxidant activity. Food Science Technology 28:25-30.

Cheng GW, Breen PJ (1991). Activity of phenylalanine ammonia-lyase (PAL) and concentrations of anthocyanins and phenolics in developing strawberry fruit. Journal of American Society of Horticultural Sciences 116:865-869.

Cunja V, Mikulic-Petkovsek M, Stampar F, Schmitzer V (2014). Compound identification of selected Rose species and cultivars: an insight to petal and leaf phenolic profiles. Journal of American Society of Horticultural Sciences 139:157-166.

Ercisli S (2005). Rose (Rosa spp.) germplasm resources of Turkey. Genetic Resources and CropEvolution 52:787-795.

Ercisli S (2007). Chemical composition of fruits in some rose (Rosa spp.) species. Food Chemistry 104:1379-1384.

Ercisli S, Güleryüz M (2005). Rose hip utilization in Turkey. Acta Horticulturae 690:77-82.

Fascella G, Giardina G, Maggiore P, Giovino A, Scibetta S (2015). Distribution, habitats, characterization and propagation of Sicilian rose species. Acta Horticulturae 1064:31-37.

Fenglin H, Ruili L, Liang M (2004). Free radical scavenging activity of extracts prepared from fresh leaves of selected Chinese medicinal plants. Fitoterapia 75:1423.

Gao X, Björk L, Trajkovski V, Uggla M (2000). Evaluation of antioxidant activities of rosehip ethanol extracts in different test systems. Journal of Science, Food and Agriculture 80:2021-2027.

Ghazghazi H, Miguel MG, Hasnaoui B, Sebei H, Figueiredo AC, Pedro LG, Barroso JG (2012). Leaf essential oil, leaf methanolic extract and rose hips carotenoids from Rosa sempervirens L. growing in North of Tunisia and their antioxidant activities. Journal of Medicinal Plants Research 6:574-579.

Ghazghazi H, Miguel MG, Hasnaoui B, Sebei H, Ksontini M, Figueiredo AC, Pedro LG, Barroso JG (2010). Phenols, essential oils and carotenoids of Rosa canina from Tunisia and their antioxidant activities. African Journal of Biotechnology 9:2709-2716.

González JA, Gallardo MG, Boero C, Cruz ML, Prado FE (2007). Altitudinal and seasonal variation of protective and photosynthetic pigments in leaves of the world's highest elevation trees Polylepis tarapacana (Rosaceae). Acta Oecologica 32:36-41.

Kähkönen MP, Hopia AI, Vuoela J, Rauha JP, Pihlaja K, Kulaja T, Heinonen M (1999). Antioxidant activity of plant extracts containing phenolic compounds. Journal of Agriculture and Food Chemistry 47:39543962.

Kalt W, Ryan DAJ, Duy JC, Prior RL, Ehlenfeldt MK, Kloet SPV (2001). Interspecific variation in anthocyanins, phenolics, and antioxidant capacity among genotypes of highbush and lowbush blueberries. Journal of Agriculture and Food Chemistry 49:4761-4767.

Kim DO, Jeong SW, Lee CY (2003). Antioxidant capacity of phenolic phytochemicals from various cultivars of plums. Food Chemistry 81(3):321-326.

Kondratyuk TP, Pezzuto JM (2004). Natural product polyphenols of relevance to human health. Pharmaceutical Biology 42:46-63.
Kovacs S, Facsar G, Udvardy L, Tóth M (2005). Phenological, morphological and pomological characteristics of some rose species found in Hungary. Acta Horticulturae 690:71-76.

Kultur S (2007). Medicinal plants used in Kirklareli Province (Turkey). Journal of Ethnopharmacology 111:341-364.

Kurtto A, Lampinen R, Junka L (2004). Atlas Florae Europaeae. Distribution of vascular plants in Europe: Rosaceae. The Committee for Mapping the Flora of Europe and Societas Biologica Fennica Vanamo, Helsinki, Finland.

Li JR, Liu J, He DH, Xu HX, Ding LS, Bao WK, ... Zhou Y (2013). Three new phenolic compounds from the leaves of Rosa sericea. Fitoterapia 84:332-337.

Lichtenthaler HK (1987). Chlorophylls and carotenoids: pigments of photosynthetic biomembranes. Methods in Enzymology 148:350-382.

Middleton E, Kandaswami C, Theoharides TC (2000). The effects of plant flavonoids on mammalian cells: implications for inflammation, heart disease and cancer. Pharmacological reviews 52:673-751.

Monder MJ, Niedzielski M, Wolinski K (2014). Effect of rooting preparations on protein, chlorophyll and carotenoid content in leaves of Rosagallica 'Duchessed'Angouleme' cuttings. Dendrobiology 72:29-39.

Nowak R, Gawlik-Dziki U (2007). Polyphenols of Rosa L. leaves extracts and their radical scavenging activity. Zeitschrift Naturforschung 62:3238.

Ouerghemmi S, Sebei H, Siracusa L, Ruberto G, Saija A, Cimino F, Cristani M(2016). Comparative study of phenolic composition and antioxidant activity of leaf extracts from three wild Rosa species grown in different Tunisia regions: Rosa canina L., Rosa moschata Herrm. and Rosa sempervirens L. Industrial Crops and Products 94:167-177.

Ozsoy N, Kultur S, Melikoglu G, Can A (2013). Screening of the antioxidant potential of the leaves and flowers from Rosa horrida Fischer. Journal of Medicinal Plants Research 7:573-578.

Parejo I, Viladomat F, Bastida J, Rosas-Romero A, Flerlage N, Burillo J, Codina C (2002). Comparison between the radical scavenging activity and antioxidant activity of six distilled and nondistilled Mediterranean herbs and aromatic plants. Journal of Agriculture and Food Chemistry 50:6882-6890.

ScalzoJ, Politi A, Pellegrini N, Mezzetti B, Battino M(2005). Plant genotype affects total antioxidant capacity and phenolic contents in fruit. Nutrition 21:207-213.

Schmitzer V, Veberic R, Osterc G, Stampar F (2010). Color and phenolic content changes during flower development in groundcover rose. Journal of American Society for Horticultural Science 135(3):195-202.

Singleton VL, Rossi JA (1965). Colorimetry of total phenolics with phosphomolybdic-phosphotungstic acid reagents. American Journal of Enology and Viticulture 16:144158.

Sparinska A, Rostoks N (2012). Comparing ornamental and other quality traits of Rosa rugos a hybrids in Latvia. Acta Horticulturae 953:277-283.

Sroka Z (2005). Antioxidative and antiradical properties of plant phenolics. Zeitschrift Naturforschung 60:833-843.

Uggla M, Martinsson (2005). Cultivate the wild roses- experiences from rose hip production in Sweden. Acta Horticulturae 690:83-90.

Wenzig EM, Widowitz U, Kunert O, Chrubasik S, Bucar F, Knauder E, Bauer R (2008). Phytochemical composition and in vitro pharmacological activity of two rose hip (Rosa canina L.) preparations. Phytomedicine 15:826-835. 